\title{
Associations between Placental Insulin-Like Growth Factor-1 Gene Expression, DNA Methylation and Intrauterine Growth Restriction
}

\author{
Xiaojuan Li"1\#, Baifeng Yü ${ }^{2 \#, ~ X u e l i ~ W u ~}{ }^{3 \S}$, Jiye Zhang1, Caihong Jia4, Zhuo Wang4, \\ Qiaomiao Zhou ${ }^{5}$, Hongtao Zhou ${ }^{1}$, Guohui Yi $^{6}$, Xinping Chen ${ }^{*}$, Shengmiao Fu ${ }^{1 \dagger}$
}

\author{
${ }^{1}$ Hainan Provincial People's Hospital Central Laboratory, Key Laboratory of Cellular and Molecular Genetic Transformation of \\ Hainan Province Medicine, Haikou, China \\ ${ }^{2}$ Department of Pediatrics, University of Utah, Salt Lake City, Utah, USA \\ ${ }^{3}$ Haikou City Maternal and Child Care Hospital Clinical Laboratory, Haikou, China \\ ${ }^{4}$ TropicalBiological Technology Research Institute, Chinese Academy of Tropical Agriculture Science, Haikou, China \\ ${ }^{5}$ Prenatal Diagnosis Center, Hainan Medical Center for Women and Children, Haikou, China \\ ${ }^{6}$ Hainan Medical College, Haikou, China \\ Email: *chenxinping@126.com, ${ }^{\dagger}$ smfu2000@126.com
}

How to cite this paper: Li, X.J., Yu, B.F., Wu, X.L., Zhang, J.Y., Jia, C.H., Wang, Z., Zhou, Q.M., Zhou, H.T., Yi, G.H., Chen, X.P. and Fu, S.M. (2020) Associations between Placental Insulin-Like Growth Factor-1 Gene Expression, DNA Methylation and Intrauterine Growth Restriction. Health, 12, 270-280.

https://doi.org/10.4236/health.2020.123022

Received: February 16, 2020

Accepted: March 21, 2020

Published: March 24, 2020

Copyright $\odot 2020$ by author(s) and Scientific Research Publishing Inc. This work is licensed under the Creative Commons Attribution International License (CC BY 4.0).

http://creativecommons.org/licenses/by/4.0/

\begin{abstract}
Intrauterine growth restriction (IUGR) is a common fetal development disorder which has great impact on neonatal health. Insulin-like growth factor-1 $(I G F 1)$ has an important role in regulating fetal growth. Whether IGF1 DNA methylation was associated with IUGR has not been studied. Placenta samples from IUGR $(\mathrm{n}=27)$ and normal delivery $(\mathrm{n}=29)$ were collected whereas basic information of mothers and infants were also collected. RT-PCR was performed to examine $I G F 1$ transcriptions and bisulfite sequencing PCR was used for DNA methylation analysis. Gene expression analysis found IUGR had significantly lower $I G F 1$ transcription compared to control group (IUGR: $0.330 \pm 0.351$; control group: $1.001 \pm 0.800, \mathrm{t}=3.995, P<0.001)$. CpG sites at the promoter region of $I G F 1$ were all highly methylated and there is no difference on DNA methylation rate between IUGR and control group (IUGR: 75\%; control group: $81 \% ; P=0.09$ ). Interestingly, in both IUGR and control groups, male fetus had significantly higher methylation rate than female fetus (IUGR: male: $87 \%$; female: $74 \%, P=0.016$; control: male: $82 \%$; female: $69 \%, P$ $=0.012$ ). There was no correlation between $I G F 1$ gene expression and DNA
\end{abstract}

\footnotetext{
\#These authors contributed equally to this work.

${ }^{\S}$ The author has passed away.

${ }^{*}, \dagger$ Corresponding authors.
} 
methylation rate $(\mathrm{r}=0.095, P=0.063)$. Intrauterine fetal growth restriction placenta had significantly lower IGFlgene expression; however, IGF1 DNA methylation level was similar. A potential fetus gender difference was also found in $I G F 1$ DNA methylation rate.

\section{Keywords}

Placental, Insulin-Like Growth Factor-1, IUGR

\section{Introduction}

Fetal growth restriction, also called intrauterine growth restriction (IUGR), is a common fetal development disorder which has great impact on neonatal health. The incidence of IUGR in China was reported to be $8.77 \%$ which equated to 1.6 million of affected neonates per year, posing a great burden on public health [1]. IUGR refers to the restricted fetal growth which is unable to reach genetic growth potential owning to pathogenic factors from maternal, placental and fetal causes. Because fetal intrauterine growth and development is difficult to monitor, so ultrasound is used to predict IUGR. Ultrasound measurement of fetal growth meridians includes: biparietal diameter, head circumference, abdominal circumference, femoral length. The fetal weight at the corresponding gestational age was calculated according to the Hadlock criterion to diagnose whether it is lower than the 10th percentile of the same fetal age to predict IUGR [2], which has been demonstrated to be the important cause for neonatal comorbidity and mortality [3]. Children with IUGR are born smaller than gestational age (SGA), the term SGA will be used exclusively to describe newborns whose birth weight is less than the 10th percentile for gestational age [4]. SGA neonates have four times or ten times higher mortality risk than infants with birth weight of 2500 - 2999 grams or 3000 - 3499 grams, respectively [5]. More importantly, intrauterine growth retardation predisposes children to a greater risk for diseases later in life. Previous studies have shown that a compromised intrauterine environment not only increased the risk of IUGR, Preeclampsia (PE), Intrauterine virus infection and malnutrition all cause IUGR in premature infants, causes the fetus to be born SGA. These children have inadequate intrauterine nutrition reserves, there were more complications after birth, prone to feeding intolerance, infection and other causes, this causes slow growth after birth, but also the risk of diseases during adulthood and led to permanent change of physiology and metabolism through modulating developmental programming [6]. Researchers have pointed out that IUGR neonates had greater risk of intellectual and physical growth retardation, insulin resistance, obesity, and diabetes later in childhood and adulthood [7] [8] [9]. It was indicated by a previous study that the insulin-like growth factor 1 (IGF1) in the umbilical cord was responsible for the growth, nutrition transportation of fetus and the placenta [10]. Hence, genetic regulation of $I G F 1$ may be important in modulating fetal growth and has a potential role in IUGR. IGF1 expression 
starts at early stage of embryo development [11]. To date, it has been acknowledged that IGFl's role on fetal development including regulating cell division, differentiation and apoptosis [12]. It also affects placental development and transportation and promotes anabolism of glucagon, protein and fats [13] [14] [15]. Previous studies also demonstrated that $I G F 1$ axis mutation led to severe fetal growth retardation [16] [17].

DNA methylation is one of the earliest found genetic modulation approaches and affects gene expression. It was found that at least $50 \%$ of gene expression was negatively associated with DNA methylation rate [18] [19]. It remained possible that DNA methylation of $I G F 1$ was associated with its gene expression and thus, affected fetal growth. In this study, we aimed to investigate the association between placental expression of $I G F 1$, its DNA methylation and IUGR.

\section{Materials and Methods}

\subsection{Patients}

Placentas from IUGR patients diagnosed between July 2012 and July 2013 were collected from Hainan province people's hospital of obstetrics. We collected samples from 27 children with IUGR who agreed to participate in this study, 5000 cases deliveries per years in this hospital. IUGR group: 14 male infants and 13 female infants, there were 4 cases of caesarean section and 23 cases of spontaneous delivery; The age of pregnant women was 20 - 39 years old, with an average of $25.6 \pm 3.4$; Pregnancy was $36-41 \mathrm{~W}$, with an average of $38.2 \pm 2.1 \mathrm{~W}$; BMI of before pregnancy: $17.57-28$, with an average of $20.1 \pm 2.4$, as shown in Table 1 . IUGR was diagnosed as a fetal weight less than the tenth percentile or two standard deviations of the average fetal weight of the same gestational age. All participants have signed consent forms.

\subsection{Placenta Tissue Samples Collection}

After the delivery, the placenta is collected from the central part of the mother's side, a small piece of placenta was dissected $(1 \mathrm{~cm} \times 1 \mathrm{~cm} \times 1 \mathrm{~cm})$ from the whole tissue by aseptic technique. The placenta tissue was then placed in RNAlater solution with diethyl pyrocarbonate (Ambion, Thermo Scientific, China) and stored in the $4^{\circ} \mathrm{C}$ freezer for overnight. Long-term storage of placenta tissue was kept under $-80^{\circ} \mathrm{C}$.

Table 1. IUGR clinical signs of the child and the mother.

\begin{tabular}{cccc}
\hline Mother & Cases & Newborn & Cases \\
\hline Nemia & 5 & Hyperbilirubinemia & 15 \\
Hepatitis B & 5 & Umbilical cord tiny & 6 \\
Preeclampsia & 6 & Umbilical cord torsion & 2 \\
Other & 11 & Umbilical hernia & 1 \\
Total & 27 & Other & 27
\end{tabular}




\subsection{DNA and RNA Extraction}

Fifty milligrams of placenta tissue was ground into mince and DNA and RNA were than extracted by the Gene and RNA extraction kit (BioTeke Corporation, Beijing, China) according to the manufacturer's instruction.

\subsection{Real-Time rtPCR}

Total RNA was reverse-transcripted into cDNA template by reverse transcription kit (TransBionovo Co., Ltd., Beijing, China). The total reaction mix was 20 $\mu \mathrm{l}$ containing $4 \mu \mathrm{l}$ of total RNA, Random Primer $1 \mu \mathrm{l}$, 2×TS Reaction Mix $10 \mu \mathrm{l}$, RT/RI Mix $1 \mu \mathrm{l}$ and RNase-free Water $4 \mu$ l. The reaction procedure was $25^{\circ} \mathrm{C}$ for 10 minutes, $42^{\circ} \mathrm{C}$ for 30 minutes, and $85^{\circ} \mathrm{C}$ for 5 minutes. cDNA was then kept under $-20^{\circ} \mathrm{C}$ freezer. Real-time PCR was performed using SYBR Green I fluorescent quantitative PCR technique. The primer pair (Sangon Biotech Co., Ltd., Shanghai, China) for IGF1 was 5'-ATGTCCTCCTCGCATCTCTTCT-3' for forward and 5'ATAAAAGCCCCTGTCTCCACAC-3' for reverse primer. The primer pair for GAPGH (housekeeping gene) was 5'-CTTTGGTATCGTGGAAGGACTC-3' for forward and 5'-GTAGAGGCAGGGATGATGTTCT-3' for reverse primer. The total reaction mix was $50 \mu \mathrm{l}$ containing $2 \mu \mathrm{l}$ of cDNA, $25 \mu \mathrm{l}$ of SYBR'Green I Real-time PCR Master Mix (BioTeke Corporation, Beijing, China) and 10 pmol of forward and reverse primers. RT-PCR was then performed by fluorescence PCR system (ABI Prism 7300 Real-Time PCR System, Applied Biosystems, the United States). The procedure was 40 cycles of $95^{\circ} \mathrm{C}$ for 15 seconds, $55^{\circ} \mathrm{C}$ for 15 seconds, and $72^{\circ} \mathrm{C}$ for 50 seconds followed by $95^{\circ} \mathrm{C}$ for 5 seconds, $60^{\circ} \mathrm{C}$ for 1 second and $95^{\circ} \mathrm{C}$ for 5 seconds for signal detection. Dissociation curve was generated by increasing the temperature from $55^{\circ} \mathrm{C}$ to $95^{\circ} \mathrm{C}$ gradually. CT values were then recorded. Real-time PCR results were processed using $2^{-\triangle \Delta C T}$ method.

\subsection{IGF1 Methylation Analysis}

Two hundred nanograms of DNA from each placenta sample were processed by bisulfite using EZ DNA Methylation-Gold Kit M (Zymo Research, CA, United States) according to manufacturer's instruction. Processed DNA sample was kept under $20^{\circ} \mathrm{C}$ before BSP (bisulfite sequencing PCR) procedure. PCR was performed on all processed DNA samples using TaKaRaEpiTaq ${ }^{\mathrm{TM}} \mathrm{HS}$ kit (Takara, Dalian, China). MethPrimer software was used for prediction of methylation status at the promoter area of $I G F 1$. [19] Nine CpG sites at the upstream region of P3 promoter region where CpG sites were clustered $(-861$ - -574$)$ were selected for methylation analysis. The forward primer was 5'-TGAGGTTATTTTGTTTGATTTGTGTAG-3' and the reverse primer was 5'-AATTTCTACTTAACCCACCCACTTAC-3' (Sangon Biotech Co., Ltd., Shanghai, China).

\subsection{DNA Cloning and Sequencing}

The PCR product was connected to pMDR18-T and transferred into E. coli $\mathrm{DH} 5 \alpha$ competent cells. Confirmed clones with PCR product were selected and plasmids were sequenced by Sangon Biotech Co., Ltd., Shanghai. Methylation 
status at each CpG site was recorded.

\subsection{Statistical Analysis}

All data analysis was performed in SPSS v17.0 (SPSS Inc, Chicago). Students' t test was used for comparing the mRNA expression level between IUGR and control groups. Comparisons on DNA methylation was performed by Chi-square Fisher's exact method. Spearman correlation analysis was used for the correlation between mRNA expression and DNA methylation. P level less than 0.05 was considered as statistically significant.

\section{Results}

We collected placenta samples from 29 normal-weight neonates and 27 IUGR infants for comparison. Control group: 17 male infants and 12 female infants, there were 9 cases of caesarean section and 20 cases of spontaneous delivery; The age of pregnant women was $20-38$ years old, with an average of $25.3 \pm 3.2$; Pregnancy was $36-41 \mathrm{~W}$, with an average of $37.2 \pm 2.5 \mathrm{~W}$; BMI of before pregnancy: 17.1 - 27.6 with an average of $20.8 \pm 2.7$, no adverse pregnancy, no hypertension, no diabetes, no smoking history, all cases were single pregnancy, No other maternal complications. There was no significant difference in maternal ages, gestational weeks and BMI between each group $(P>0.05)$ (Table 2).

\subsection{Placental mRNA Expressions of IGF1}

The mRNA transcripts of $I G F 1$ from placenta from IUGR and those from control group were compared. Results showed that lower mRNA transcription of $I G F 1$ was demonstrated in the IUGR group. The relative transcription levels of IUGR were $33 \%$ of that of control group (IUGR: $0.330 \pm 0.351$; control group: $1.001 \pm$ $0.800)$ (Figure 1$)$, which was statistically significant $(\mathrm{t}=3.995, P<0.001)$.

\subsection{Methylation Analysis of IGF1}

No CpGisland was found within the promoter region of IGFlas predicted by Methprimer software. Nine CpG sites upstream of the promoter (CpG1 to CpG9) where $\mathrm{CpG}$ sites were more accumulated were than selected for methylation analysis. BSP analysis showed that both IUGR and control group IGF1 were highly methylated (IUGR: 75\%; control group: 81\%; $P=0.09$ ) (Figure 2 and Figure 3). However, there as a significantly higher methylation rate found in the placenta of male fetus than female fetus in the control groups (male: $87 \%$; female: $74 \%, P$ $=0.016$ ). Similar trend was also found in the IUGR group where the male fetus had higher $I G F 1$ methylation rate than female fetus (male: $82 \%$; female: $69 \%, P=$ 0.012). Overall, placenta from male fetus had significantly higher rate for meIGF1 methylation than the female fetus (Figure 4). In the IUGR group, the PE group methylation rate was $85 \%$, the non-PE group methylation rate was $71 \%$, there were significant differences between the two groups $(P=0.06)$. 
Table 2. Results of normal control and IUGR.

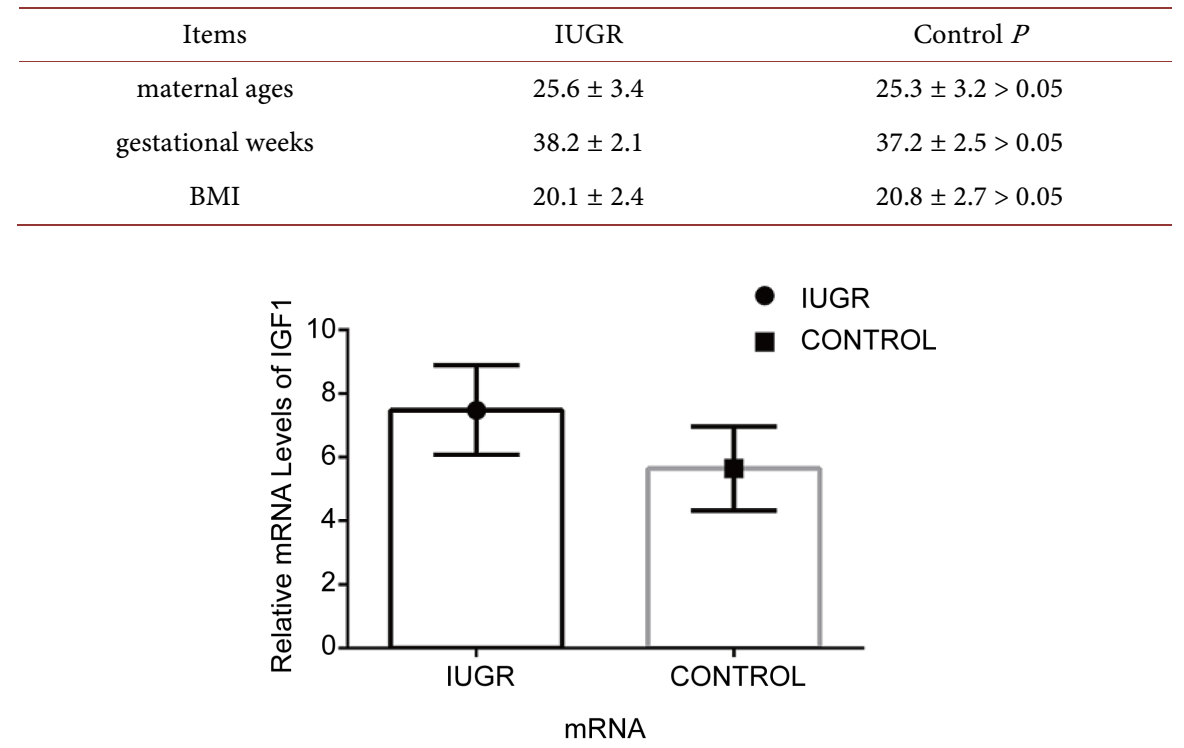

Figure 1. mRNA expressions of IGFI in the placenta from IUGR $(\mathrm{n}=27)$ and control $(\mathrm{n}=29)$ groups. ${ }^{\star *} P<0.001$; IUGR: intrauterine growth retardation.

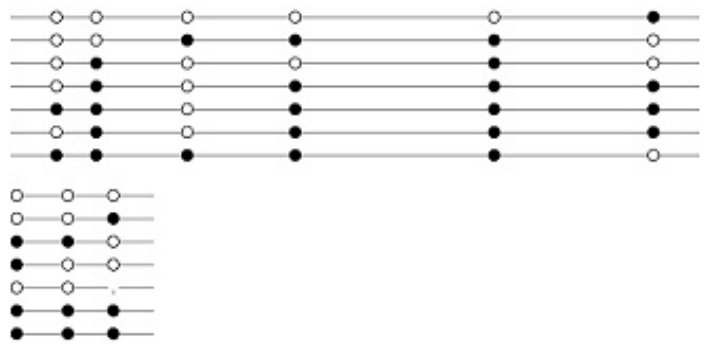

Figure 2. The results of sequencing after cloning were analyzed by using BiQ_Analyzer. IGFI DNA methylation analysis at the CpG sites by BSP method. White circle: demethylatedCpG; black circle: methylated CpG; BSP: bisulfite sequencing PCR (Methylation primer: forward primer 5'-TGAGGTTATTTTGTTTGATTTGTGTAG-3'; reverse primer 5'-AATTTCTACTTAACCCACCCACTTAC-3').

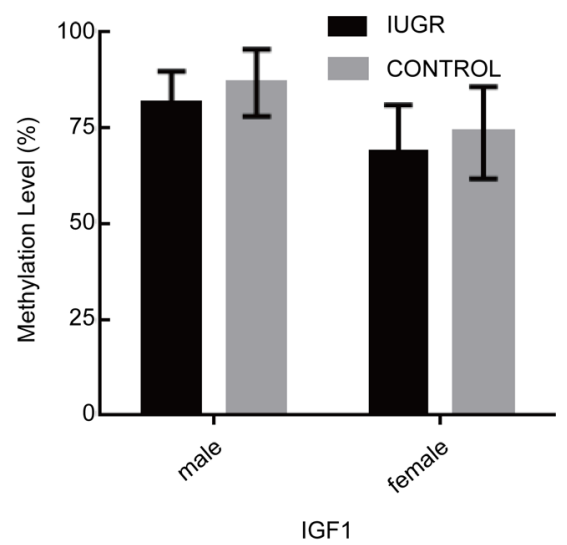

Figure 3. IGFI DNA methylation level between fetus genders in IUGR and control groups. IUGR: intrauterine growth retardation. 


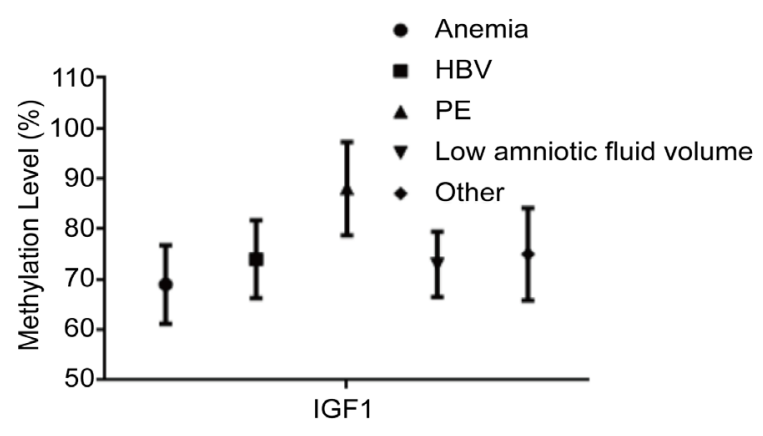

Figure 4. IGFI DNA methylation level Comparison of different influencing factors. IUGR: intrauterine growth retardation.

\subsection{Association between mRNA Transcription and DNA Methylation of IGF1}

Although the mRNA transcriptions of $I G F 1$ were significantly different between IUGR and control groups, there is no significant association between mRNA transcription levels and the methylation rates of $I G F 1(\mathrm{r}=0.095, P=0.063)$.

\section{Discussion}

This study demonstrated that the placenta from IUGR fetus had significantly lower $I G F 1$ transcription levels. The IUGR placenta showed lower IGF1 transcription level) with a $66 \%$ reduction found in IUGR group compared to control group. A homozygous partial deletion of the $I G F 1$ gene was demonstrated in a case with poor fetal growth and persistent postnatal physical growth retardation [20]. More recently a Greek study also demonstrated reduced gene expressions of $I G F 1$ and its binding protein in IUGR placentas [21]. Our results are consistent with previous study and support the important role of $I G F 1$ in maintaining normal fetal growth. However, our results demonstrated no significant correlation between $I G F 1$ gene expression and its DNA methylation rate. (A decreased transcription level) was not associated with IGF1DNA methylation status. Instead, a potential fetus's gender effect may modulate DNA methylation rate. As suggested by Kaiser et al., DNA methylation and gene expression might not be a simple linear relationship, but rather a threshold relationship [22]. Higher methylation inhibits gene expression whereas low methylation state enables gene expression [23], although the level of expression might also be affected by other factors. A previously published investigation by our group found that $I G F 1$ expression reduced in infants with a birth weight higher than 4260 grams without changes in DNA methylation rate [24]. Our data also showed that IGF1 gene had no CpGisland where CpG sites are mostly demethylated [25]. This high methylation rate may change the position of nucleosome, thus affecting gene expression [26]. The results of our study argue against the association between IGFlexpression and its DNA methylation, Similar results were also reported in other studies. Turan et al.reported a lack of association between gene expression and DNA methylation in 23 growth related genes [27]. Similar trends were also found in E-cadherin, GADgene and DLC1 gene [28] [29] [30]. 
This study identified a fetus gender difference in $I G F 1$ DNA methylation rate with a higher methylation rate found in male fetus placenta from both IUGR and control groups. Gender has been demonstrated to be an important modulator for DNA methylation and DNA methylation could deactivate $\mathrm{X}$ chromosome [30] [31]. Q Fu et al. has pointed out that the gender difference in IGF1 DNA methylation may be associated with histone code modification [32], which can combine with different protein or protein complex under different circumstances and change the relevant gene expressions. More recent studies also suggested that gender difference in DNA methylation was also affected by multiple factors [33] [34].

In addition, we found that the methylation rate of IUGR varies with different factors.

There were 8 cases of PE on among the children with IUGR, and these had higher rates of placental methylation [35]. Jane $\mathrm{W}$ et al. found that the IGF1 promoter region of the placenta was hypermethylated in PE patients, which is consistent with our study, PE is one of the important causes of IUGR [36]. The invasion of $\mathrm{E}$ trophoblast cells into the spiral artery was limited, and the failure of placental vascularization leads to placental ischemia and hypoxia [37]. Severe hypoxia alters the epigenetic characteristics of the human placental trophoblast in culture [38]. Therefore, IGFl of PE patients in the IUGR group showed hypermethylation. In conclusion, our study has demonstrated that intrauterine fetal growth retardation placenta had significantly lower $I G F 1$ gene expression. There was no difference in DNA methylation between IUGR and control placentas, and DNA methylation was not associated with $I G F 1$ gene expression levels. The methylation rate of IUGR caused by different factors was different. IUGR is the result of a variety of factors, and the causes of fetal growth restriction are complex. Therefore, we cannot use a single mechanism to measure the disease. However, a fetal gender difference in IGF1 DNA methylation rate was noted; its significance in $I G F 1$ gene regulation needs further elucidation. Future study on placenta whole genome analysis could give more information on genetic network on fetal growth regulation.

\section{Acknowledgements}

Supported by Nature Science Foundation of Hainan Province (No. 811182).

\section{Conflicts of Interest}

The authors declare no conflicts of interest regarding the publication of this paper.

\section{References}

[1] Liu, J., et al. (2014) The Incidence Rate, High-Risk Factors, and Short- and Long-Term Adverse Outcomes of Fetal Growth Restriction: A Report from Mainland China. Medicine, 93, e210. https://doi.org/10.1097/MD.0000000000000210

[2] Longo, S., et al. (2013) Short-Term and Long-Term Sequelae in Intrauterine Growth 
Retardation (IUGR). The Journal of Maternal-Fetal \& Neonatal Medicine, 26, 222-225. https://doi.org/10.3109/14767058.2012.715006

[3] RM, K. (2011) Intrauterine Growth Restriction. In: Fanaroff and Martin's Neonatal Perinatal Medicine, Elsevier, Mosby, MO, 245-275.

[4] ACOG (2019) Practice Bulletin No. 204. Fetal Growth Restriction. Obstetrics \& Gynecology.

[5] Ashworth, A. (1998) Effects of Intrauterine Growth Retardation on Mortality and Morbidity in Infants and Young Children. European Journal of Clinical Nutrition, 52, S34-S41.

[6] Salam, R.A., Das, J.K. and Bhutta, Z.A. (2014) Impact of Intrauterine Growth Restriction on Long-Term Health. Current Opinion Clinical Nutrition Metabolic Care, 17, 249-254. https://doi.org/10.1097/MCO.0000000000000051

[7] Mi, J., et al. (2000) Effects of Infant Birthweight and Maternal Body Mass Index in Pregnancy on Components of the Insulin Resistance Syndrome in China. Annals of Internal Medicine, 132, 253-260.

https://doi.org/10.7326/0003-4819-132-4-200002150-00002

[8] Hack, M., et al. (2002) Outcomes in Young Adulthood for Very-Low-Birth-Weight Infants. The New England Journal of Medicine, 346, 149-157. https://doi.org/10.1056/NEJMoa010856

[9] Tenhola, S., et al. (2005) Serum Markers of GH and Insulin Action in 12-Year-Old Children Born Small for Gestational Age. European Journal of Endocrinology, 152, 335-340. https://doi.org/10.1530/eje.1.01869

[10] Servoss, S.J., et al. (2001) IGF-I as a Mediator of VIP/Activity-Dependent Neurotrophic Factor-Stimulated Embryonic Growth. Endocrinology, 142, 3348-3353. https://doi.org/10.1210/endo.142.8.8335

[11] Han, V.K., et al. (1988) Expression of Somatomedin/Insulin-Like Growth Factor Messenger Ribonucleic Acids in the Human Fetus: Identification, Characterization, and TISSUE DISTRIBution. The Journal of Clinical Endocrinology \& Metabolism, 66, 422-429. https://doi.org/10.1210/jcem-66-2-422

[12] Hwa, V., et al. (2013) IGF-I in Human Growth: Lessons from Defects in the GH-IGF-I Axis. Nestlé Nutrition Institute Workshop Series, 71, 43-55. https://doi.org/10.1159/000342548

[13] Pawshe, C.H., Rao, K.B. and Totey, S.M. (1998) Effect of Insulin-Like Growth Factor I and Its Interaction with Gonadotropins on in Vitro Maturation and Embryonic Development, Cell Proliferation, and Biosynthetic Activity of Cumulus-Oocyte Complexes and Granulosa Cells in Buffalo. Molecular Reproduction and Development, 49, 277-285.

https://doi.org/10.1002/(SICI)1098-2795(199803)49:3<277::AID-MRD8>3.0.CO;2-L

[14] Prelle, K., et al. (2001) Insulin-Like Growth Factor I (IGF-I) and Long R(3)IGF-I Differently Affect Development and Messenger Ribonucleic Acid Abundance for IGF-Binding Proteins and Type I IGF Receptors in in Vitro Produced Bovine Embryos. Endocrinology, 142, 1309-1316. https://doi.org/10.1210/endo.142.3.8038

[15] Froesch, E.R., et al. (1985) Actions of Insulin-Like Growth Factors. Annual Review of Physiology, 47, 443-467. https://doi.org/10.1146/annurev.ph.47.030185.002303

[16] Gannage-Yared, M.H., et al. (2013) Homozygous Mutation of the IGF1 Receptor Gene in a Patient with Severe Pre- and Postnatal Growth Failure and Congenital Malformations. European Journal of Endocrinology, 168, K1-K7.

https://doi.org/10.1530/EJE-12-0701 
[17] Woods, K.A., et al. (1996) Intrauterine Growth Retardation and Postnatal Growth Failure Associated with Deletion of the Insulin-Like Growth Factor I Gene. The New England Journal of Medicine, 335, 1363-1367. https://doi.org/10.1056/NEJM199610313351805

[18] Bell, J.T., et al. (2011) DNA Methylation Patterns Associate with Genetic and Gene Expression Variation in HapMap Cell Lines. Genome Biology, 12, R10. https://doi.org/10.1186/gb-2011-12-1-r10

[19] Rakyan, V.K., et al. (2008) An Integrated Resource for Genome-Wide Identification and Analysis of Human Tissue-Specific Differentially Methylated Regions (tDMRs). Genome Research, 18, 1518-1529. https://doi.org/10.1101/gr.077479.108

[20] Li, L.C. and Dahiya, R. (2002) MethPrimer: Designing Primers for Methylation PCRs. Bioinformatics, 18, 1427-1431. https://doi.org/10.1093/bioinformatics/18.11.1427

[21] Koutsaki, M., et al. (2011) Decreased Placental Expression of hPGH, IGF-I and IGFBP-1 in Pregnancies Complicated by Fetal Growth Restriction. Growth Hormone \& IGF Research, 21, 31-36. https://doi.org/10.1016/j.ghir.2010.12.002

[22] Kaiser, M.F., et al. (2013) Global Methylation Analysis Identifies Prognostically Important Epigenetically Inactivated Tumor Suppressor Genes in Multiple Myeloma. Blood, 122, 219-226. https://doi.org/10.1182/blood-2013-03-487884

[23] Jones, P.A. and Baylin, S.B. (2002) The Fundamental Role of Epigenetic Events in Cancer. Nature Reviews Genetics, 3, 415-428. https://doi.org/10.1038/nrg816

[24] Zhang, J., et al. (2015) Correlation of Insulin-Like Growth Factor 1 Expression in Placenta with DNA Methylation and Fetal Macrosomia. Chinese Journal of Medical Genetics, 32, 36-39.

[25] Cottrell, S.E. (2004) Molecular Diagnostic Applications of DNA Methylation Technology. Clinical Biochemistry, 37, 595-604. https://doi.org/10.1016/j.clinbiochem.2004.05.010

[26] Fatemi, M., et al. (2005) Footprinting of Mammalian Promoters: Use of a CpG DNA Methyltransferase Revealing Nucleosome Positions at a Single Molecule Level. Nucleic Acids Research, 33, e176. https://doi.org/10.1093/nar/gnil80

[27] Turan, N., et al. (2012) DNA Methylation Differences at Growth Related Genes Correlate with Birth Weight: A Molecular Signature Linked to Developmental Origins of Adult Disease? BMC Medical Genomics, 5, 10. https://doi.org/10.1186/1755-8794-5-10

[28] Park, J.H., et al. (2008) Hypermethylation of E-Cadherin in Endometrial Carcinoma. Journal of Gynecological Oncology, 19, 241-245. https://doi.org/10.3802/jgo.2008.19.4.241

[29] Huang, H.S. and Akbarian, S. (2007) GAD1 mRNA Expression and DNA Methylation in Prefrontal Cortex of Subjects with Schizophrenia. PLoS ONE, 2, e809. https://doi.org/10.1371/journal.pone.0000809

[30] Sarter, B., et al. (2005) Sex Differential in Methylation Patterns of Selected Genes in Singapore Chinese. Human Genetics, 117, 402-403. https://doi.org/10.1007/s00439-005-1317-9

[31] Reddington, J.P., Pennings, S. and Meehan, R.R. (2013) Non-Canonical Functions of the DNA Methylome in Gene Regulation. Biochemical Journal, 451, 13-23. https://doi.org/10.1042/BJ20121585

[32] Fu, Q., et al. (2009) Epigenetics: Intrauterine Growth Retardation (IUGR) Modifies the Histone Code along the Rat Hepatic IGF-1 Gene. FASEB Journal, 23, 2438-2449. https://doi.org/10.1096/fj.08-124768

[33] Hall, E., et al. (2014) Sex Differences in the Genome-Wide DNA Methylation Pat- 
tern and Impact on Gene Expression, microRNA Levels and Insulin Secretion in Human Pancreatic Islets. Genome Biology, 15, 522. https://doi.org/10.1186/s13059-014-0522-Z

[34] McCarthy, N.S., et al. (2014) Meta-Analysis of Human Methylation Data for Evidence of Sex-Specific Autosomal Patterns. BMC Genomics, 15, 981. https://doi.org/10.1186/1471-2164-15-981

[35] Min, M., et al. (2018) Preeclampsia Is Associated with Hypermethylation of IGF-1 Promoter Mediated by DNMT1. American Journal of Translational Research, 10, 16-39

[36] Jane, W., et al. (2011) Is Fetal Growth Restriction Associated with a More Severe Maternal Phenotype in the Setting of Early Onset Pre-Eclampsia? A Retrospective Study. PLoS ONE, 6, 1-5. https://doi.org/10.1371/journal.pone.0026937

[37] Palei, A.C., et al. (2013) Pathophysiology of Hypertension in Pre-Eclampsia: A Lesson in Integrative Physiology. Acta Physiologica, 208, 224-233. https://doi.org/10.1111/apha.12106

[38] Yuen, R.K., et al. (2013) Hypoxia Alters the Epigenetic Profile in Cultured Human Placental Trophoblasts. EPI-Genetics, 8, 192-202.

https://doi.org/10.4161/epi.23400 